\title{
CAMPUH KODE BASA BALI KUNO-BASA SANSKERTA RING PUPULAN PRASASTI BALI KUNO WARSA 882-914 MASEHI
}

\author{
Kd. Dwi Swandana', I Kt. Paramarta ${ }^{1}$, IB. Putra Manik A² \\ Jurusan Pendidikan Bahasa Bali \\ Universitas Pendidikan Ganesha \\ Singaraja, Indonesia

\begin{abstract}
e-mail: \{dwiswandana@gmail.com,ketutgembel@yahoo.co.id, putramanikaryana@gmail.com\}@undiksha.ac.id
\end{abstract}

\begin{abstract}
Kuub
Tetilikan puniki matetujon mahbahang (1) soroh campuh kode manut undagan kruna sajeroning prasasti Bali Kuno warsa 882-914 masehi, (2) soroh campuh kode manut pawiwit basa sajeroning prasasti Bali Kuno warsa 882-914 masehi, lan (3) pawesana (faktor) sane ngawinang campuh kode sajeroning prasasti Bali Kuno warsa 882-914 masehi. Jejering tetilikan inggih punika prasasti Bali Kuno saking warsa 882-914 masehi. Panandang tetilikan inggih punika campuh kode. Kramaning tetilikan sane kaanggen minakadi dokumentasi lan sadu wicara. Data tureksa sane kaanggen sakadi mastikayang data, reduksi data, nyorohang data lan panyutetan. Pikolih tetilikan minakadi, (1) soroh campuh kode manut undagan kruna, sekadi campuh kode marupa kruna lingga lan campuh kode marupa kruna tiron, (2) soroh campuh kode manut pawiwit basa kapolihang data campuh kode sane mawiwit saking basa Sanskerta, (3) pawesana (faktor) sane ngawinang campuh kode, sekadi parindikan saking sang sane mabaos lan parindikan basa.
\end{abstract}

Kruna Jejaton: campuh kode, prasasti Bali Kuno

\begin{abstract}
Abstrak
Penelitian ini bertujuan menguraikan (1) jenis campur kode menurut tingkatan kata dalam prasasti Bali Kuno tahun 882-914 masehi, (2) jenis campur kode menurut asal bahasa dalam parasasti Bali Kuno tahun 882-914 masehi, (3) faktor yang menyebabkan campur kode dalam prasasti Bali Kuno tahun 882-914 masehi. Subjek penelitian adalah prasasti Bali Kuno dari tahun 882-914 masehi. Objek penelitian adalah campur kode. Metode penelitian yang digunakan yaitu dokumentasi dan wawancara. Analisis data yang digunakan seperti identifikasi data, reduksi data, klasifikasi data dan kesimpulan. Hasil penelitian yaitu, (1) jenis campur kode menurut tingkatan kata, yaitu campur kode berupa kata dasar dan campur kode berbentuk kata berimbuhan, (2) jenis campur kode menurut asal bahasa didapatkan data campur kode yang berasal dari bahasa Sanskerta, (3) faktor yang menyebabkan campur kode, yaitu faktor penutur dan faktor kebahasaan
\end{abstract}

Kata Kunci : campur kode, prasasti Bali Kuno 


\begin{abstract}
This study aims to describe (1) code mixing type according to the word level in the ancient Balinese inscription 882-914 AD, (2) mixed code type according to the language origin in the ancient Balinese inscription 882-914 AD, (3) the factor causing mixed code in the ancient Balinese inscription 882-914 AD. Research subject is ancient Balinese inscription from 882-914 AD. Research object is mixed code. Research method used is documentation and interview. Data analysis used such as data identification, data reduction, data classification and conclusions. Research result is (1) code mixing type according to the word level, mixed code in word base form and mixed code in affixed word form, (2) mixed code type according to the language origin obtained mixed code data that derived from Sanskrit, (3) factors that cause mixed code, ie speaker factor and linguistic factor.
\end{abstract}

Keywords : mix code, ancient Balinese inscription

\section{PURWAKA}

Basa Bali wantah sinalih tunggil basa daerah sane wenten ring panegara Indonesia. Basa Bali punika kaanggen piranti mabebaosan olih krama Bali. Basa Bali mangkin sane kasengguh basa Bali Anyar (modern) sampun akeh kaiusin olih akeh panglimbak basa sane lianan. Indik panglimbak basa Bali sadurung sakadi mangkin kakepah dados tigang panglimbak sane kawastanin aab (periodisasi) panglimbak basa Bali. Tigang pahan panglimbak punika (1) basa Bali sane akeh keni iusan kosa basa Sanskerta sane sering kasengguh basa Bali Kuno, (2) basa Bali sane kosa basanyane akeh kapanggihin kosa basa Jawa lan kosa basa Jawa Kuno sane kasengguh basa Bali Tengahan, (3) basa Bali sane kosa basanyane nenten wantah kacampuhin olih kosa basa Sanskerta lan Jawa Kuno kemanten, nanging sampun akeh kapanggihin kosa basa Indonesia, Cina, taler basa dura negara sane lianan kasengguh basa Bali Anyar (modern) (Bawa Is, 1985: 21).

Maosang indik kawentenan basa Bali Kuno mapaiketan sareng tradisi lan budaya kuno sane wenten ring Bali. Basa Bali Kuno nenten prasida lempas sareng kawentenan prasasti Bali Kuno. Prasasti punika pinaka genah nyurat sakancan kauripan lan budaya krama Bali duke punika. Punika mawinan ring prasasti
Bali Kuno wenten tampak tetamian ngenenin indik kawentenan basa Bali Kuno.

Goris (1954) nemuang wenten 37 prasasti mabasa Bali Kuno sane mijil ngawit warsa 882-1050 masehi. Basa Bali Kuno akeh kaiusin olih basa Sanskerta maka wesana panglimbak Hindu-India ka Bali. Manut praktiasa riin lan panampen Bawa, akehnyane iusan basa Sanskerta ring basa Bali Kuno pinih akeh kapanggihin ring aab pangriin prasasti mabasa Bali Kuno inggih punika ring warsa 882-914 masehi. Prasasti sane mijil sasampun duke punika nenten kaiusin olih basa Sanskerta kemanten nanging taler sampun akeh nerima iusan saking basa Jawa Kuno.

Salami warsa 882-914 masehi kapanggahin 7 prasasti mabasa Bali Kuno punika (1) prasasti Sukawana Al sane magenah desa Sukawana kecamatan Kintamani kabupaten Bangli, (2) prasasti Bebetin Al sane magenah ring desa Bebetin kecamatan Sawan kabupaten Buleleng, (3) prasasti Trunjan AI magenah ring desa Trunyan Bangli, (4) prasasti Trunjan B taler magenah ring desa Trunyan, (5) prasasti Bangli, Pura Kehen A2 magenah ring desa Cempaga pura Kehen kecamatan Bangli, (6) prasasti Gobleg Pura Desa I magenah ring desa Gobleg kecamatan Banjar kabupaten Buleleng, lan (7) prasasti Angsari A sane magenah ring desa Angseri 
kecamatan Penebel kabupaten Tabanan. Sajeroning prasasti-prasasti punika nenten kasurat indik sapasira raja ring aab prasasti punika.

Maka bukti iusan basa Sanskerta sajeroning basa Bali Kuno prasida kacingak ring prasasti Sukawana A1 (882 Masehi) sane kasengguh pinaka prasasti pinih kuno. Punggelan daging prasasti punika kasurat sakadi ring sor.

Yumu pakatahu sarbwa kiha, dinganga prajuna nāyakan makarun kumpi anan mañuratang ājñā danañjaya, pircintayangku mān tua ulan di bukit (Sukawana A1, 882 M. $001 \mathrm{lb} 1)$.

'ida dane sareng sami mangda uning parajana sane dados prajuru, sane dados prajuru manggala paruman inggih punika Kumpi Anan mrentah Danañjaya dados juru surat pamrentahan, sane kayunang titiang (dane singgih) inggih punika pesanggrahan ring bukit'

Sajeroning punggelan prasasti punika wenten kruna nāyakan 'prajuru utawi manggala', sarbwa 'sami', ājña 'prentah utawi pituduh' lan kruna pircintayangku 'sane kakayunang titiang (dane singgih). Kruna nāyakan mawit saking basa Sanskerta nayaka 'manggala', sarbwa mawit saking kruna sarve 'sami', ājña sane mawit saking kruna ajJa 'prentah' lan kruna pircintayangku mawit saking kruna cinta 'kayun'. Indike punika nujuang wenten iusan basa Sanskerta ring basa Bali Kuno.

Manut praktiasa data riin ring prasasti Sukawana punika prasida kacingak wenten kalih basa inggih punika basa Bali Kuno lan basa Sanskerta. Iusan Sanskerta ring basa Bali Kuno puniki ngawinang wenten pacampuhan kalih warna basa inggih punika pantaraning basa Bali Kuno lan basa Sanskerta.

Kawentenan pacampuhan warna basa sajeroning panglimbak basa Bali nenten prasida kakelidin, basa Bali sampun saking dumun nerima iusan saking basa lianan sakadi basa Sanskerta, Jawa Kuno lan Tengahan, Cina, Portugis, Belanda, Ian Inggris. Kawentenan pacampuhan warna (kode) basa duk aab basa Bali Kuno nglantur kantos aab basa Bali Anyar (modern). Basa Bali Anyar (modern) sajabaning kantun ngwarisin pacampuhan warna (kode) basa saking panglimbak sadurungnyane taler sampun kabuktiang akeh macampuh warna basannyane sareng basa Indonesia lan Inggris. Indike punika kabuktiang saking tetilikan asoroh sane mamurda Campuh Kode Ring Koran Bali Post Rahina Redite Pamijilan NovemberDesember Warsa 2015 sane akeh kapanggihin kosa basa Indonesia lan basa dura negara (Inggris) sane ngiusin basa Bali (Prabandari, 2016). Salanturnyane kabuktiang ring tetilikan sane mamurda Campuh Kode Ring Tembang Pop Bali Bahagia Itu Sederhana Olih Leeyonk Sinatra taler akeh kapanggihin kosa basa Indonesia lan basa dura negara (Inggris) sane ngiusin basa Bali (Widiastuti, 2016).

Madasar antuk bebahbahan ring dadalan pikobet punika, tetilikan sane matetujon nyinahang campuh kode sajeroning panglimbak basa Bali pamekas ring basa Bali Kuno dahat mabuat kalaksanayang. Madasar antuk tetimbangan punika, panilik nglaksanayang tetilikan sane mamurda Campuh Kode Basa Bali Kuno-Basa Sanskerta Ring Pupulan Prasasti Bali Kuno Warsa 882-914 Masehi.

Bantang pikobet tetilikan: (1) Napi manten soroh campuh kode manut undagan kruna sajeroning prasasti Bali Kuno warsa 882-914 masehi?, (2) Napi manten soroh campuh kode manut pawiwit basa sajeroning prasasti Bali Kuno warsa 882-914 masehi?, (3) Napi sane ngawinang campuh kode sajeroning prasasti Bali Kuno warsa 882-914 masehi?

Tetujon tetilikan puniki inggih punika minakadi: (1) Mangda prasida 
mahbahang soroh campuh kode manut undagan kruna sajeroning prasasti Bali Kuno warsa 882-914 masehi, (2) Mangda prasida mahbahang soroh campuh kode manut pawiwit prasasti sajeroning basa Bali Kuno warsa 882-914 masehi, (3) Mangda prasida mahbahang sane ngawinang campuh kode sajeroning prasasti Bali Kuno warsa 882-914 masehi

Ring sajeroning tetilikan puniki wenten kawigunannyane, minakadi kawigunan pamucuk lan kawigunan panglimbak sane kabahbahang sakadi ring sor

Kawigunan Pamucuk (teoritis) ring tetilikan puniki inggih punika mangda prasida ngicenin kawruhan lan nglimbakang dasar tetimbangan ngenenin sosiolinguistik pamekasnyane indik campuh kode sajeroning prasasti Bali Kuno warsa 882-914 masehi. Kawigunan Panglimbak (praktis) tetilikan puniki inggih punika minakadi: (1) Majeng ring Panilik sane matetujon pikolih tetilikan puniki mangda prasida ngabinayang ngenenin indik soroh campuh kode sane wenten ring prasasti Bali Kuno lan uning pawesana sane ngawinang kawentenan campuh kode sajeroning prasasti Bali Kuno warsa 882-914 masehi, (2) Majeng ring Panilik Lianan,pikolih tetilikan puniki kaaptiang prasida kaanggen imba olih panilik lianan sane madue arsa pacang nglaksanayang tetilikan sane masaih utawi mesib sareng tetilikan puniki. Tetilikan puniki taler kaaptiang prasida dados dasar lan pratiwimba ri tatkala nglaksanayang tetilikan sane lianan lan mapaiketan sareng campuh kode, (3) Majeng ring Para Mahasisia, tetilikan puniki kaaptiang prasida kaanggen nincapang kawagedan paplajahan ring mata kuliah sosiolinguistik. Mangda mahasisia punika uning tur ngresepang indik materi sane ngawinang kawentenan campuh kode. Tetilikan indik campuh kode puniki mangda prasida kaanggen sarana, sasuluh utawi tetimbangan tetilikan sane pacang kalaksanayang

Tetilikan sane kaselehin ngenenin indik campuh kode basa Bali Kuno-basa Sanskerta ring pupulan prasasti Bali Kuno warsa 882-914 masehi puniki mahbahang landaasan teori sakadi: kedwibahasaan (bilingualisme), campuh kode; soroh campuh kode; dadalan campuh kode; basa Bali Kuno; prasasti basa Bali Kuno lan basa Sanskerta.

Kedwibahasaan utawi bilingualisme inggih punika kawentenan jadma sane waged ring kalih basa ri tatkala mabebaosan lan kawagedan soang-soang basa punika nenten musti sawaged basa ibunyane. Jadma sane waged nganggen kalih basa punika kasengguh dwibahasawan.

Campuh kode inggih punika panutur sane nganggen basa daerahnyane minakadi basa daerah Bali lan nyisipang basa Indonesia utawi basa daerah lianan ring sajeroning bebaosannyane, prasida kabaosang panutur punika sampun nganggen campuh kode.

Soroh-soroh campuh kode wenten kalih inggih punika manut pawiwit basa lan manut wangun kerta basa (Jendra, 1991: 132). Campuh kode manut pawiwit basa kakepah dados tiga inggih punika campuh kode ke tengah, campuh kode ka sisi, lan campuh kode cecampuhan. Campuh kode manut wangun kerta basa kakepah dados tiga inggih punika campuh kode sajeroning wangun kruna, campuh kode sajeroning wangun frase, lan campuh kode sajeroning wangun klausa

Dadalan Campuh Kode manut Jendra (1991: 142) wenten tigang parindikan sane dados dadalan utawi sane ngawinang campuh kode. Tigang parindikan punika minakadi sang sane mabaos, basa sane kaanggen, lan tetujon bebaosan. Indike punika malih kasaderanaang 
dados kalih, inggih punika sang sane mabaos dados parindikan saking sang sane mabaos lan basa sane kaanggen lan tetujon bebaosan dados parindikan basa

Basa Bali Kuno inggih punika parinama basa Bali duk aab sane kuno. Basa Bali kuno puniki kapanggihin sajeroning prasastiprasasti sane mijil ring aab Bali Kuno punika (Granoka, 1984: 1). Basa Bali Kuno sane kaanggen sajeroning prasasti-prasasti punika malianan sareng basa Bali Kuno lisan sarahina inggihan wangun lan aab pangawigunannyane. Kantos mangkin durung wenten kapanggihin ragam/warna lianan sareng kawentenan ring prasasti-prasasti punika. Salanturnyane, manut Bawa (2002: 16) basa Bali Kuno inggih punika basa sane kapanggihin sajeroning prasasti-prasasti ring Bali. Kantos mangkin, manut Goris (1954a) wenten 37 prasasti sane mabasa Bali Kuno.

Prasasti inggih punika marupa piagam (sane kasurat ring batu, tembaga lan sane lianan). Asapunika taler ring prasasti Bali Kuno, prasasti Bali Kuno pinaka genah nyurat sakancan kauripan lan budaya krama Bali duke punika sane kasurat antuk basa Bali Kuno. Prasasti sane mabasa Bali Kuno wenten 37 prasasti (Goris, 1954). Prasasti-prasasti punika mijil ring warsa sane malianan lan mawit saking raja sane malianan.

Basa Sanskerta inggih punika sinalih tunggil rumpun basa IndoEropa sane pinih purwa sane kantun kauningin lan lelintihannyane pinih dawa. Basa Sanskerta nglimbak ring Indonesia maka wesana panglimbak Hindu-India ring abad ka 5. Salanturnyane kebudayaan Hindu sampun jaya ring abad ka 7 kabuktiang antuk akeh kerajaan Hindu duke punika. Prasida katarka indik panglimbak basa Sanskerta duke punika mabuat kantos mangkin.

\section{KRAMANING TETILIKAN}

Manut Wendra (2014: 31), kramaning tetilikan inggih punika dudonan sane kalaksanayang ri tatkala nyawis pikobet sane kalaksanayang. Kramaning tetilikan punika kakepah dados 6 inggih punika, (1) palihan tetilikan, (2) jejering lan panandang tetilikan, (3) parikrama mupulang data, (4) piranti tetilikan, (5) data tureksa.

Palihan tetilikan ring tetilikan puniki inggih punika deskriptif kualitatif sane prasida sane nyinahang indik campuh kode basa Bali Kuno-basa Sanskerta ring pupulan prasasti Bali Kuno warsa 882-914 masehi. Jejering tetilikan puniki inggih punika prasasti Bali Kuno warsa 882-914 masehi. Panandang tetilikan ring tetilikan puniki inggih punika campuh kode.

Parikrama mupulang data sane kaanggen ring tetilikan puniki inggih punika nganggen kalih parikrama minakadi kramaning dokumentasi lan kramaning sadu wicara. Piranti sane kaanggen sajeroning tetilikan puniki inggih punika kaanutang sareng pikobet sane jagi kabahbahang minakadi piranti dokumentasi pamekasnyane ri kala nyalin (ngetik) teks prasasti nganggen panuntun tata sesuratan manut Goris miwah kartu data lan piranti sadu wicara marupa daftar pitaken sane katujuang ring pegawai Balai Arkeologi utawi sujana Bali Kuno miwah marupa HP (handphone) sane kaanggen ngerekam kramaning sadu wicara saking panampen pegawai Balai Arkeologi utawi sujana basa Bali Kuno. Sane kaping untat data tureksa sane kaanggen sajeroning tetilikan puniki inggih punika mastikayang data (identifikasi data), nyorohang data (klasifikasi data), reduksi data lan pamicutet (kesimpulan).

\section{PIKOLIH LAN TETEPASAN}

Pikolih lan tetepasan tetilikan saking tetiga bantang pikobet inggih punika (1) soroh campuh kode manut 
undagan kruna sajeroning prasasti Bali Kuno warsa 882-914 masehi, (2) soroh campuh kode manut pawiwit basa sajeroning prasasti Bali Kuno warsa 882-914 masehi, lan (3) pawesana (faktor) sane ngawinang campuh kode sajeroning prasasti Bali Kuno warsa 882-914 masehi.

Campuh kode manut undagan kruna utawi wangun kruna prasida mawangun kruna lingga (kata dasar), kruna dwi lingga (kata ulang), kruna satma (kata majemuk) lan kruna tiron (kata berimbuhan) (Jendra, 1991: 136). Sajeroning tetilikan puniki kapolihang 34 data sane marupa campuh kode ring undagan kruna. Data-data punika prasida kakepah dados kalih soroh inggih punika data campuh kode marupa wangun kruna lingga lan sane marupa kruna tiron. Campuh kode undagan kruna sane marupa kruna lingga akehnyane 26 data lan sane marupa kruna tiron 9 data. Data campuh kode manut undagan kruna sane marupa kruna lingga sajeroning tetilikan puniki inggih punika sarbwa, nāyaka, dukha/ duhkha, sāksī, ājñā, hetu, senapati, bhikṣu, satra, grama/ grāma, bhangsi/ bhangçi, prakāra, tapa, çaka, uparata, suddha/ çuddha, caturthi, pancami, krsna, nawami, bhagi/ bhāgi, tambrabhajaña, çukla, pakșa, ratha lan ya. Data campuh kode manut undagan kruna sane marupa kruna tiron ring tetilikan puniki inggih punika nāyakan, pircintayangku, parbhangçi, çimayangña, patapān, partapanān, habhagi/ habhāgi, sesan/ sesaña lan pūjān.

Kruna sarbwa punika yening cingakin ring kamus Sankserta witnyane sarve 'sami/ samian', taler ring kamus basa Bali Kuno sakadi punika artosnyane. Kruna sarbwa lan sarve puniki madue kasumaihan struktur sareng artosnyane. Yening selehin ring imba punggelan prasasti Sukawana Al inggih punika yumu pakatahu sarbwa kiha 'ida dane sareng sami/ samian mangda uning parajana sane dados prajuru'
(Sukawana A1, 882 M. 001 lb 1). Salanturnyane kruna nāyaka punika maartos manggala, imbanyane ring punggelan prasasti Trunjan Al inggih punika nāyaka sākșī 'manggala saksi/ pasaksian' (Trunjan Al, 833M. 003 Ila 3). Kruna salanturnyane inggih punika kruna dukha utawi duhkha sane maartos sebet, meweh, imbanyane sakadi ring punggelan prasasti Bebetin Al inggih punika mula dukha 'wit meweh' (Bebetin Al, 818M. 002 II b 2). Kruna salanturnyane inggih punika sāksī 'saksi/ pasaksian', sane kapolihang ring sesuratan prasasti nāyaka nāyaka 'manggala saksi/ pasaksian' (Trunjan Al, 833M. 003 Ila 3). Data salanturnyane inggih punika ājñā 'prentah', pinaka imba sesuratan kruna punika ring prasasti inggih punika mañuratang ājñā danañjaya 'mrentah dananjaya dados juru tulis' (Sukawana Al, 818M. 001 lb 1). Kruna campuh kode undagan kruna marupa kruna lingga salanturnyane inggih punika hetu 'awinan' imbanyane sakadi ring punggelan prasasti punika ya hetu syuruḥku kumpi siddhi 'punika awinan titiang (dane singgih) ngandikain kumpi siddhi' (Trunjan Al, 833M. 003 lb 2). Kruna salanturnyane senapati 'panglima', indike puniki kabuktiang ring sesuratan punggelan prasasti inggih punika senāpati danda kumpi 'panglima kumpi danda' (Sukawana Al, 818M. 001 1b 2). Kruna Sanskerta salanturnyane inggih punika bhikșu 'pandita', imbanyane sakadi sesuratan puniki me bhikșu widya ruwana 'lan pandita widya ruwana' (Bebetin Al, 818M. 002 lb 2). Kruna satra yening cingakin ring kamus maartos genah mararian, ring kamus basa bali Kuno maartos pasanggrahan. Genah mararian punika sareng pasanggrahan madue paiketan teges inggih punika genah mararian punika marupa pasanggrahan. Pinaka imba sesuratan satra sakadi ring punggelan prasasti puniki banguněn partapanān satra di katahan buru 'mangda kawangun pasanggrahan para patapa 
ring genah maboros' (Sukawana Al, 818M. $001 \mathrm{lb} 3$ ). Salanturnyane inggih punika kruna grama/ grāma 'krama', imbanyane inggih punika grama musirang ya marumah ditu 'krama ngungsi sane meneng irika' (Sukawana Al, 818M. $001 \mathrm{lb}$ 5). Kruna salanturnyane sane ngranjing ring basa Sankserta inggih punika bhangsi/ bhangçi 'suling', yening cingakin ring kamus Sanskerta kruna punika witnyane vamzi 'suling'. Kruna bhangsi lan vamzi punika madue kasumaihan struktur lan teges sane nenten mauwah. Kruna prakāra 'sakancannya' sane prasida kacingakin ring imba sesuratan punggelan prasasti sakadi pamahen pamli prakāra 'naur sane katumbas lan sakancannya' (Bebetin Al, $818 \mathrm{M}$. 002 Ila 2). Kruna salanturnyane inggih punika tapa 'tapa, pertapaan', kruna puniki saking struktur kantun manggeh ring artosnyane sane pateh. Imbanyane prasida kacingak sakadi punggelan sesuratan prasasti puniki pabharu di tapa haji "krama anyar sane meneng ring pertapaan raja' (Sukawana Al, 818M. 001 lla 4). Kruna çaka 'warsa, çaka' taler nenten nguwah struktur lan teges sane kantun manggeh. Imbanyane sakadi sesuratan prasasti puniki di çaka 804 kilagiña di putthaging ājñā 'ring warsa çaka 804 kasuratang prentah olih raja' (Sukawana Al, 818M. 001 Illa 2). Kruna salanturnyane sane marupa kruna Sanskerta inggih punika uparata 'upacara ala mati', imbanyane inggih punika ana uparata ta anak marumah ditu 'wenten upacara ala mati ring anak sane meneng irika'. Kruna sane kruna linggaa Sanskerta salanturnyane inggih punika suddha/ çuddha 'suci', indike puniki kabuktiang sasampune nyingakin ring kamus Sanskerta lan kamus Bali Kuno artosnyane manggeh. Imba sesuratan prasastinyane sakadi puniki bhikșu suddha ganitriña 'pandita suci sane durung marabian' (Trunjan Al, 833M. 003 IIla 2). Salanturnyane kapanggihin caturthi 'rahina kaping pat', imbanyane ring sesuratan punggelan prasasti puniki di bulan āsaddha çukla caturthi rggas pasar bwijayamanggala 'ring bulan suci roras rahina pasaran beteng kaping pat' (Trunjan Al, 833M. 003 IVa 3). Kruna salanturnyane inggih punika pancami 'tanggal lima', imbanyane ring punggelan prasasti puniki di bulan besakha çukla pañcami 'ring bulan suci paro terang tanggal lima' (Bebetin Al, 818M. 002 Illb 1). Kruna sane ngranjing ring Sanskerta sane sampun lumbrah inggih punika krsna 'ireng' sane prasida kapanggih ring punggelan sesuratan prasasti puniki bulan asuji krsna 'bulan kaping tiga peteng (tilem)'(Trunjan B, 833M. 004 Ilb 4). Kruna ireng wenten paiketan teges sareng peteng utawi tilem punika. Kruna salanturnyane inggih punika nawami 'kaping sia', yening cingakin ring kamus Sanskerta witnyane saking navami sane manggeh maartos kaping sia. Imbanyane prasida kacingak ring punggelan sesuratan prasasti puniki di bulan bhadrawada krsna nawami 'ring bulan kaping kalih sajeroning awarsa saka nepek ri kala tilem kaping sia' (Gobleg, Pura Desa I, 836M. 006 Ila 5). Kruna salanturnyane sane kantun katami kantos mangkin marupa kruna Sanskerta inggih punika bhagi/ bhāgi 'baga, eduman', imbanyane sakadi ring punggelan sesuratan prasasti puniki inggih punika maruhani dua bhagi 'lanang polih duang eduman/ baga' (Sukawana Al, 818M. 001 llb 1). Salanturnyane inggih punika kruna tambrabhajaña 'lempengan tembaga', yening selehin ring kamus Sanskerta kruna punika minabang gabungan saking kruna tamra 'tembaga' lan bhajana 'piringan' sane ngwangun artos sane nenten doh malianan. Kruna Sanskerta sane lianan sane sampun lumbrah inggih punika çukla 'terang, suci', imbanyane sakadi sesuratan prasasti puniki inggih punika di bulan besakha çukla pañcami 'ring bulan suci paro terang tanggal lima' (Bebetin Al, 818M. 002 
Illb 1). Kruna salanturnyane sane ngranjing basa Sanskerta inggih punika pakșa 'bulan paruh' sakadi sesuratan prasasti puniki di bulan așādha çukla pakșa rggas pasar bwijayamanggala 'ring bulan suci paruh roras rahina pasaran beteng'. Kruna lingga Sanskerta sane lianan inggih punika ratha 'kereta', sesuratannyane prasida kacingak ring punggelan prasasti inggih punika mañuratang ratha 'manyurat kereta' (Trunjan Al, 833M. 003 lb 3). Salanturnyane sane kaping untat kruna lingga sane ngranjing ring Sanskerta inggih punika ya 'punika', yening cingakin ring kamus Bali kuno artos ya punika wenten kalih inggih punika 'punika' lan 'ya sane nujuang jadma'. Dadosnyane data sane kaambil ring tetepasan kruna ya puniki wantah sane anut sareng artos ring Sanskerta. Imbanyane sakadi ya hetu syuruḥku kumpi siddhi 'punika awinan titiang (dane singgih) ngandikain kumpi siddhi' (Trunjan Al, 833M. 003 lb 2)

Tetepasan data campuh kode manut undagan kruna sane marupa kruna tiron ring tetilikan puniki inggih punika nāyakan, pircintayangku, parbhangçi, çimayangña, patapān, partapanān, habhagi/ habhāgi, sesan/ sesaña lan pūjān. Sakadi sane sampun kauningin indik kruna tiron punika wantah kruna sane sampun polih wewehan. Kruna nāyakan yening cingakin ring kamus Bali Kuno maartos manggala, ring kamus Sanskerta wenten kruna nāyaka 'manggala'. Sinah wenten marupa wewehan (pangiring) $\mathrm{n}$ ring ungkur kruna nāyaka punika. Yening dadosang pola inggih punika nāyaka + $\mathrm{n}=$ nāyakan. Punika nyinahang wenten pacampuhan pantaraning kruna Sanskerta nāyaka sareng pangiring $n$ sane ngamanggehang arots manggala. Imba sesuratan kruna punika sakadi ring punggelan prasasti puniki inggih punika nāyakan makarun cagu 'manggala persidangan inggih punika Cagu' (Trunjan Al,
833M. $003 \mathrm{lb}$ 1). Kruna tiron salanturnyane inggih punika pircintayangku 'sane kakayunang titiang (dane singgih)', yening bahbahang dados pir + cinta + yang + ku, kruna cinta yening rereh ring kamus Sanskerta kruna cinta maartos 'kayun'. Kruna cinta punika polih pangater pir, iringan yang lan polih kruna pangentos jadma kapertama ku. Pangater pir ring ajeng kruna cinta ngwangun kruna kriya linaksana saking morfem dasar. Imbanyane sakadi sesuratan puniki pircintayangku mān tua ulan di bukit 'sane kakayunang titiang (dane singgih) inggih punika pasanggrahan ring bukit' (Sukawana Al, 818M. 001 lb 1). Kruna salanturnyane inggih punika parbhangçi, witnyane saking kruna bhangçi/ vamzi 'suling', sane polih pangater par. Ring tata basa Bali Kuno pangater par wigunannyane wantah ngwangun pelakul jadma. Sinah parbhangçi inggih punika marupa kruna aran sane artosnyane tukang suling. Kruna tiron salanturnyane wantah çimayangña 'sane watesnyane' sane mawiwit saking kruna çima 'wates' polih iringan yang lan ña. Imbanyane sakadi ring sesuratan prasasti puniki inggih punika çimayangña hangga tingkad karuh 'watesnyane kantos tukad ring sisi kauh' (Sukawana Al, 818M. $001 \mathrm{lb}$ 3). Kruna salanturnyane inggih punika patapān 'genah matapa' sane witnyane saking kruna tapa polih pangater pa lan pangiring an. Pangater pa sajeroning basa bali Kuno madue kawigunan ngwangun kruna aran, asapunika taler pangiring an sane ngwangun kruna aran. Patapān 'genah matapa' wantah kruna aran, imbanyane sakadi ring sesuratan punggelan prasasti puniki inggih punika patapān songan bunga 'genah matapa songan bunga' (Trunjan Al, 833M. 003 Illb 3). Kruna tiron salanturnyane inggih punika partapanān 'tukang matapa' sane witnyane saking kruna tapa polih pangater par lan pangiring nan. 
Pangater par ring ajeng mawiguna anggen ngwangun kruna aran minakadi pelaku/ jadma. Partapanān wantah sang sane matapa utawi tukang tapa. Imbanyane sakadi sesuratan punggelan prasasti puniki inggih punika bangunĕn partapanān satra di katahan buru 'kawangun pesanggarahan olih tukang tapa ring genah maboros' (Sukawana Al, 818M. $001 \mathrm{lb} 3$ ). Pikolih salanturnyane sane jagi katepasin inggih punika kruna habhagi/ habhāgi 'aduman/ 1 bagian'. Kruna punika mawiwit saking kruna bhāgi lan pangater ha, pangater ha nujuang asiki, salanturnyane kruna bhāgi witnyane sane basa Sanskerta inggih punika baga sane artosnyane taler manggeh eduman/ bagian. Pinaka imba sesuratanyane ring prasasti inggih punika babini habhagi 'majeng ring rabi/ istri aduman' (Trunjan Al, 833M. 003 Illa 5). Kruna tiron salanturnyane sane ngranjing ring campuh kode inggih punika sesan/ sesaña 'sisan/ sisannyane'. Wit kruna puniki wantah sesa (zesa ring kamus Sanskerta online) 'sisa' sane polih pangiring $\mathrm{n}$ lan pangiring ña. Imbanyane inggih punika sesan yalapña marhantuangña panekĕn di hyang api 'sisannyane kaambil anggen pangutangan lan kaaturang ring hyang api' (Sukawana Al, 818M. $001 \mathrm{llb} 3$ ). Kruna sane kaping untat inggih punika pūjān 'sembah' sane mawiwit saking kruna puja polih pangiring $n$, kruna puja taler maartos sembah. Imbanyane sakadi sesuratan punggelan prasasti puniki kunang yanada yanada pūjān sang ratu di guha 'salanturnyane yening wenten sembah sang ratu ring goa' (Trunjan Al, 833 M. 003 llb 4).

Sajeroning pikolih lan tetepasan indik soroh campuh kode manut undagan kruna sajeroning prasasti Bali Kuno warsa 882-914 masehi sampun prasida nyantenang iusan kruna-kruna Sanskerta duk warsa prasasti 882-914 masehi punika dahat mabuat pisan majeng ring panglimbak basa Bali Kuno.
Panilik taler cumpu lan nuut panampen Bawa sane maosang basa Bali Kuno wantah basa Bali sane akeh kaiusin olih basa Sanskerta, nanging panampen Bawa punika nenten mahbahang iusan basa Sanskerta manut undagan kruna marupa wangun kruna lingga lan kruna tiron. Malarapan antuk sinalih tunggil tetilikan sane sampun kapolihang lan katepasin olih panilik puniki utaminnyane ring prasasti pangriin (882-914 masehi) mahbahang iusan punika marupa kode-kode pamekas kruna-kruna Sanskerta lan cecampuhan sane sampun kakepah dados kalih inggih punika kruna lingga lan kruna tiron. Bukti-bukti basa Sanskerta sane marupa kruna Sanskerta (lingga + tiron) sane sampun macampuh sareng basa Bali Kuno dahat kabuatang sajeroning nyinahang panglimbak basa Bali.

Salanturnyane pikolih campuh kode manut pawiwit basa. Campuh kode manut pawiwit basa kakepah dados tiga inggih punika campuh kode ke tengah, campuh kode ka sisi, lan campuh kode cecampuhan(Jendra, 1991: 132). Sajeroning tetilikan puniki sane taler kawatesin antuk murda wantah nyelehin campuh kode basa Bali Kuno lan basa Sanskerta sane nenten serumpun, sinah wantah ngamolihang campuh kode manut pawiwit basa ka sisi duaning basa Bali Kuno nenten serumpun sareng basa Sanskerta (rumpun Indo-Eropa).

Tetepasan campuh kode manut pawiwit basa kakepah dados tiga inggih punika campuh kode ke tengah, campuh kode ka sisi, lan campuh kode cecampuhan. Sajeroning tetilikan puniki sane taler kawatesin antuk murda wantah nyelehin campuh kode basa Bali Kuno lan basa Sanskerta sane nenten serumpun, sinah wantah ngamoling campuh kode manut pawiwit basa ka sisi duaning basa Bali Kuno nenten serumpun sareng basa Sanskerta (rumpun Indo-Eropa). 
Salanturnyane pikolih campuh kode manut pawiwit basa marupa campuh kode ka sisi puniki akehnyane 35 data luire sarbwa, nāyaka, dukha/ duhkha, sāksī, ājñā, hetu, senapati, bhikșu, satra, grama/ grāma, bhangsi/ bhangçi, prakāra, tapa, çaka, uparata, suddha/ çuddha, caturthi, pancami, krsna, nawami, bhagi/ bhāgi, tambrabhajaña, çukla, pakșa, ratha, ya, nāyakan, pircintayangku, parbhangçi, çimayangña, patapān, partapanān, habhagi/ habhāgi, sesan/ sesaña lan pūjān. Pikolih puniki sampun katepasin sakadi ring pikolih campuh kode manut undagan kruna ring ajeng.

Sakadi dasar tetimbangan sane maosang basa Sanskerta sampun ngranjing ka Indonesia ring abad kapertama lan abad kapitu, indik campuh kode manut pawiwit basa pamekas basa Bali Kuno-basa Sanskerta sampun prasida muktiang. Pamekas punika ring prasasti Bali Kuno 882-914 masehi (abad ka 9). Akeh kode-kode Sanskerta sane ngiusin basa bali Kuno. Taler basa Sanskerta sampun masikian (bertintegrasi) sareng kawentenan basa Bali Kuno turmaning sampun katami kantos mangkin ring kawentenan basa Bali Anyar (modern).

Manut Jendra (1991: 142) parindikan sane ngawinang campuh kode inggih punika parindikan saking sang sane mabaos lan parindikan basa. Parindikan saking sang sane mabaos sane dados dadalan campuh kode minakadi sang sane mabaos, sang sane kairing mabaos, lan parisolah sang sane mabaos. Parindikan basa, sang sane mabaos sajeroning nganggen basannyane, sering nyampuhang basa lianan ring bebaosannyane mangda parindikan sane pacang kawedarang gelis karesepang. Kawentenan campuh kode pantaraning basa Bali Kuno lan basa Sanskerta sajeroning prasasti Bali Kuno, majanten sampun sinah antuk data-data sane sampun kawedar ring ajeng. Irika sampun macihna indik basa Sanskerta dahat ngiusan basa Bali Kuno duke punika. Parindikan sane ngawinang pacampuhan kode-kode punika wantah parindikan saking sang sane mabaos, parindikan basa lan parisolah sang sane mabaos punika.

Pikolih saking kramaning sadu wicara sareng narawakya pegawai Balai Arkeologi utawi sujana basa Bali Kuno (Drs. I Wayan Sunarya) ring rahina Soma, 8 Mei 2017 magenah ring Kantor Balai Arkeologi, Desa Sesetan, Kecamatan Denpasar Selatan, Kabupaten Kodya Denpasar. Manut narawakya sane mawasta Drs. I Nyoman Sunarya, pawesana sane ngawinang campuh kode sajeroning prasasti Bali Kuno minakadi sang sane mabaos lan parindikan basa. Parindikan saking sang sane mabaosnyane sakadi krama Bali lan krama tamiu pamekas pangadol saking India duke punika nganggen basa Bali Kuno taler pangadol saking India ngiusin basa Sanskerta punika ring tengah kawentenan basa Bali Kuno punika. Interakasi punika wenten ri tatkala wenten transaksi jual beli. Parindikan saking basa minakadi basa Sanskerta duke punika dangan karesepang olih krama Bali, napi malih ring bali duke punika sampun nganutin sistem kerajaan. Akehan parinama-parinama sane ngiusin basa Bali Kuno ngenenin indik birokrasi pamrentahan. Punika nyinahang krama Bali duke punika akeh nuutin/ meniru parinama-parinama saking basa Sanskerta punika

Saking bebahbahan punika prasida kacutetang pawesana sane ngawinang kawentenan campuh kode sajeroning prasasti Bali Kuno saking warsa 882-914 masehi saking kramaning dokumentsi lan sadu wicara sane sampun kamargiang, kapolihang data indik pawesana sane ngawinang campuh kode sajeroning prasasti Bali Kuno saking warsa 882914 masehi kapolihang 2 pawesana 
inggih punika parindikan saking sang

\section{PAMUPUT}

Saking pikolih lan tetepasan sane sampun kabahbahang ring ajeng, prasida katingkesang indik campuh kode manut undagan kruna kapolihang 34 data. Datadata punika prasida kakepah dados kalih soroh inggih punika data campuh kode marupa wangun kruna lingga lan sane marupa kruna tiron. Campuh kode undagan kruna sane marupa kruna lingga akehnyane 26 data lan sane marupa kruna tiron 9 data. Soroh campuh kode manut pawiwit basa kapolihang 35 data sane mawiwit saking basa Sanskerta.

Pawesana sane ngawinang campuh kode sajeroning prasasti basa Bali Kuno saking warsa 882-914 masehi inggih punika kapolihang saking kramaning dokumentasi saking panilik lan kramaning sadu wicara saking narawakya sane untengnyane pateh. Pawesana punika minakadi parindikan basa lan parindikan saking sang sane mabaos.

Piteket kawedarang majeng ring: (1) Majeng ring panilik kaaptiang pikolih tetilikan puniki mangda prasida ngabinayang ngenenin indik wangun lan soroh campuh kode sane wenten sajeroning Prasasti Bali Kuno lan uning pawesana (faktor) sane ngawinang kawentenan campuh kode ring prasasti punika; (2) Majeng ring panilik sane lianan kaaptiang mangda prasida nglimbakang tetilikan puniki pamekas nglanturang tetilikan ring Prasasti Bali Kuno sausan warsa 882-914 masehi. Panglimbak sane kaaptiang inggih punika mangda nglaksanayang tetilikan sane asoroh utawi sane lianan, sinalih tunggilnyane ngeninin indik campuh kode sajeroning prasasti basa Bali Kuno. Indike punika kaaptiang kalaksanayang mangda wenten sandingan pikolih tetilikan sajeroning prasasti- sane mabaos miwah parindikan basa.

prasasti Bali Kuno sane lianan salanturnyane

\section{DAFTAR PUSTAKA}

Arikunto, Suharsini. 2005. Manajemen Penelitian. Jakarta: Rineka Cipta.

2006. Prosedur Penelitian Suatu Pendekatan Praktik. Jakarta:

Aslinda dan Leni Syafyahya. 2010. Pengantar Sosiolinguistik. Bandung:

Bawa, I Wayan. 2002. Sejarah Perkembangan Bahasa Bali. Denpasar: Penerbit Universitas Udayana.

------. dkk. 1985. Studi Sejarah Bahasa Bali. Denpasar: Pemerintah

Chaer, Abdul. 1994. Linguistik Umum. Jakarta: Rineka Cipta.

2010. Sosiolinguistik Perkenalan Awal. Jakarta: PT Rineka Cipta.

Goris, Roelof. 1954. Prasasti Bali. Bandung: Lembaga Bahasa dan Budaja Universitet Indonesia.

Iqbal, Hasan. 2002. Pokok-Pokok Materi Metodologi Penelitian dan

Jendra, I Wayan. 1991. Dasar-dasar Sosiolinguistik. Denpasar: Ikayana.

Listiani, Ni Made Prabandari. 2016. Campuh Kode Sane Wenten Ring Rong Bali Orti Koran Bali Post Rahina Redite Pamijilan NovemberDesember Warsa 2015. Singaraja: e-journal JPBB. Vol 3, No. 1: 1-10

Nababan, P.W.J. 1991. Sosiolinguistik suatu Pengantar. Jakarta: PT

Oka Granoka, dkk. 1985. Kamus Bahasa Bali Kuno-Indonesia. Denpasar: Proyek Pengembangan Bahasa dan Sastra Indonesia dan Daerah.

Sugiyono. 2013. Metode Penelitian Kuantitatif, Kualitatif, Dan R\&D.

Sutjiati Beratha, Ni Luh. 1992. "Evolution Of Verbal Morphology In Balinese". 
Tesis. Canberra: The Australian International Unversity.

Wendra, I Wayan. 2014. Buku Ajar Penulisan Karya IImiah. Singaraja: UNDIKSHA

Widiastuti, Ida Ayu Kade. 2016. Kawentenan Campuh Kode Ring Pupulan Tembang Pop Bali Bahagia Itu Sederhana Olih Leeyonk Sinatra. Singaraja: e-journal JPBB. Vol 3, No. 1: 1-12. 